\title{
ANTIHYPERLIPIDEMIC EFFECT OF THE ETHANOL EXTRACT FRACTION FROM MULBERRY (MORUS AUSTRALIS POIR.) LEAVES ON RATS INDUCED HIGH FAT-DIET (HFD) AND PROPYLTHIOURACIL (PTU)
}

\section{PRISKA ERNESTINA TENDA ${ }^{*}$, ELEONORA MARYETA TOYO ${ }^{2}$, ARBA PRAMUNDITA RAMADANI ${ }^{3}$}

1Pharmacy Study Program, Health Polytechnic of Ministry of Health in Kupang, Indonesia ${ }^{2}$ Nusaputera College of Pharmacy, Semarang, Central Java, Indonesia, ${ }^{3}$ Department of Pharmacy, Universitas Islam Indonesia, Yogyakarta, Indonesia

"Email: priskafarmasikupang@gmail.com

Received: 15 Aug 2021, Revised and Accepted: 25 Sep 2021

ABSTRACT

Objectives: To evaluate the effect of extract and its fraction (n-hexane, ethyl acetate, and water) of the mulberry leaf (Morus australis Poir.) in reducing triglyceride and total cholesterol levels on HFD and PTU induced rats.

Methods: In this study, mulberry leaves were collected from East Nusa Tenggara-Indonesia, extracted using maceration method, and fractionated with various solvents. The thin layer chromatography with silica gel 60 F254 was utilized to identify the active compound on both extract and fraction. Furthermore, using a quasi-experimental with control group design, this study employed 40 healthy male Wistar rats and divided into 8 groups, namely: normal and negative control, positive controls (simvastatin and gemfibrozil), ethanolic extract, and fractions (n-hexane, ethyl acetate, and water). All groups were fed with a high cholesterol diet and $0.01 \%$ PTU, except for the normal group. During the study, the blood was drawn at day 0, 28, 35, and 42. The triglyceride level was observed using Glycerophosphate-0xidase Phenol Aminoantipyrine (GPO-PAP) method, while the total cholesterol was measured by Cholesterol Oxidase Phenol Aminoantipyrine (CHOD-PAP).

Results: On the $42^{\text {nd }}$ day, ethyl fraction of mulberry leaf (Morus australis Poir.) showed the most significant result of reducing the level of triglyceride and total cholesterol compared to the high-fat diet and PTU induced rat on day 0: triglyceride of $104.89 \pm 2.70 \mathrm{mg} / \mathrm{dl} \mathrm{vs} 64.76 \pm 1.97$ $\mathrm{mg} / \mathrm{dl}$ and total cholesterol of $96.70 \pm 2.45 \mathrm{vs} 88.02 \pm 1.38 \mathrm{mg} / \mathrm{dl}$. Ethyl acetate fraction was similar to simvastatin in lowering the level of total cholesterol. TLC identification also showed that mulberry leaf contains flavonoids and polyphenols that act as anti-hyperlipidemic.

Conclusion: Ethyl acetate fraction of mulberry leaf (Morus australis Poir.) showed best activity on lowering both triglyceride and total cholesterol.

Keywords: Anti-hyperlipidemia, Ethanol extract fraction, Morus australis Poir, Mulberry

(C) 2021 The Authors. Published by Innovare Academic Sciences Pvt Ltd. Thisis an open access article under theCC BYlicense (https://creativecommons.org/licenses/by/4.0/) DOI: https://dx.doi.org/10.22159/ijap.2021.v13s4.43847 Journal homepage: https://innovareacademics.in/journals/index.php/ijap

\section{INTRODUCTION}

Hyperlipidemia is a condition that is characterized by elevation of lipid levels within the body and increases the risk of cardiovascular disease [1, 2]. The efforts to reduce cholesterol levels include regulating diet, practicing regular exercise, and administering drugs [3]. Although many drugs have been established for lipid-lowering activity, prolonged use and high possibility of its side effects led to an urgency to investigate an alternative treatment. Medicinal plants that are traditionally used for preventing and treating various diseases are believed to have lower side effects and are affordable for the population [4].

Mulberry belongs to the Morus genus and is widely found in diverse climatic environments [5]. Its leaf is empirically used for various ailments including hypolipidemic activity. A study reported that mulberry possessed antioxidant, antidiabetic, and antihyperlipidemic activity [6]. Further research found that it contains flavonoid and polyphenol that may be associated with its anti-hyperlipidemic activity [7]. Modulation of gene expression related to lipid metabolism was concluded on mulberry anti-hyperlipidemic activity [8]. Therefore, this study focused on anti-hyperlipidemic activity of mulberry leaf (Morus australis Poir) from East Nusa Tenggara that have different constituents to those already studied.

\section{MATERIALS AND METHODS}

This research was a quasi-experimental study with control group design using male Wistar rats as animal study. This study evaluated the extract and fraction of mulberry leaves in reducing triglyceride and total cholesterol levels. It involved several steps including extract and fraction preparation, active compound identification, and antihyperlipidemic assay.

\section{Materials}

The materials in this study were ethyl acetate (Merck), formic acid (Merck), acetic acid glacial (Merck), dimethylamine (Merck), toluene
(Merck), and PTU (OGB Dexa), ethanol 10\% (Bratachem), $n$-hexane (Bratachem). All reagents were pharmaceutical graded.

\section{Extraction and fractionation process}

The mulberry leaves (M. australis Poir.) has been collected from Mbay area, Nagekeo Regency, East Nusa Tenggara (NTT), Indonesia in August 2019. The leaves were green-colored, fresh, and intact. Its authentication process was performed at Faculty of Pharmacy, Universitas Setia Budi, Surakarta. The determination letter was issued under reference no. 113/DET/UPT-LAB/12/XI/2019.

The gathered leaves then washed under the running water, dried in the cabinet dryer, and grounded into powder. For the amount 2000 grams of grounded mulberry leaves was placed into dark container and added $70 \%$ of ethanol with a ratio 1:10. During the first $6 \mathrm{~h}$, it stirred occasionally and left for the next $18 \mathrm{~h}$. Continuing the process, it then filtered, evaporated using a rotary evaporator $\left(50{ }^{\circ} \mathrm{C}\right)$, and yielded $18.99 \%$ of thick extract.

The fractionation process started with dissolving 10 grams of the extract with a small amount of water, partitioned with $50 \mathrm{ml}$ of water and $50 \mathrm{ml}$ of $\mathrm{n}$-hexane in a separating funnel, and repeated three times. To obtain the n-hexane fraction, the top layer was separated, evaporated using a rotary evaporator, and resulted in $11.70 \%$ of the fraction. For the bottom layer, it fractionated with $50 \mathrm{ml}$ of ethyl acetate and repeated for three times. This separation process resulted in ethyl acetate fraction on the top layer and generated $7.5 \%$ of fraction after being evaporated. The remaining filtrate was then concentrated and produced $75.29 \%$ of water fraction.

\section{Phytochemical identification}

Active compound investigation of mulberry leaves covered flavonoid, alkaloid, and polyphenols detection. The identification of flavonoids was conducted by TLC method using Silica Gel 60 F254 
for the stationary phase and combination of ethyl acetate eluent: formic acid: glacial acetic acid: water as mobile phase. The TLC plates were then sprayed using citroborate reagent resulting yellow color under $366 \mathrm{~nm}$ UV light. Rutin was utilized as standard control of flavonoid.

Meanwhile, for alkaloids, the mobile phase was a combination of toluene eluent: ethyl acetate: diethylamine. The TLC spot of alkaloids was stained by a Dragendorff reagent that generates orange color under $366 \mathrm{~nm}$ UV light. Quinine was utilized as standard control for alkaloids. Furthermore, the polyphenol detection was elucidated by ethyl acetate eluent: formic acid: toluene: water and compared to tannins as standard. The greenblack or dark blue spot appears after the plate is sprayed with $\mathrm{FeCl}_{3}$.

\section{Antihyperlipidemic assay}

This experiment employed 40 healthy male Wistar rats (2-3 mo, 180-250 grams). The animals were kept under controlled conditions at temperature $22 \pm 25{ }^{\circ} \mathrm{C}, 55 \pm 10 \%$ of humidity, and $12 \mathrm{~h}$ of dark and light cycle, fed with standard diet and water ad libitum. All the animal procedures have been approved by the ethical committee of Faculty of Medicine, Universitas Sebelas Maret, Surakarta, Indonesia (reference no. 894/XI/HREC/2019). The animals were divided into several groups as follow: normal group (standard diet), $500 \mathrm{mg} / \mathrm{kg}$ BW of mulberry ethanol extract (MEE), $60 \mathrm{mg} / \mathrm{kg}$ BW of n-hexane fraction (NHF), $40 \mathrm{mg}$ of ethyl acetate fraction (EAF), $400 \mathrm{mg} / \mathrm{kg} \mathrm{BW}$ of water fraction (WF), $0.9 \mathrm{mg} / \mathrm{kg} \mathrm{BW}$ of simvastatin and gemfibrozil as positive control group, and $0.5 \% \mathrm{Na} \mathrm{CMC}$ as negative control group. Except the normal groups, all animals were induced with a combination of high fatty diet (HFD) and $0.01 \%$ PTU for $28 \mathrm{~d}$ to achieve the hypercholesterolemia condition. The HFD was prepared by homogeneously mixing 200 gr of Comfeed PAR-S, 100 gr of flour, $8 \mathrm{gr}$ of cholesterol, $0.8 \mathrm{gr}$ of cholic acid, $40 \mathrm{ml}$ of pork oil, and $51.2 \mathrm{ml}$ of water. The mixture then made into pellets and dried to administered orally to the animals.

After hyperlipidemia status was reached, the extract and fraction then administered for $14 \mathrm{~d}$. To observe the lipid level, the blood was orbitally punctured before the induction (baseline), on day $28^{\text {th }}, 35^{\text {th }}$

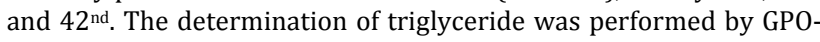
PAP and total cholesterol by CHOD-PAP in the laboratory of Center for Food and Nutrition Studies, Universitas Gadjah Mada, Yogyakarta, Indonesia.

\section{Statistical analysis}

This study resulted in both qualitative and quantitative data. For qualitative data, the phytochemical identification was analyzed by comparing the TLC spot with standard control. Meanwhile, the quantitative data, the level of triglyceride and total cholesterol were presented using mean \pm SD and analyzed using two-way Anova to assess its differences on each group.

\section{RESULTS}

The active compound of mulberry extract and fraction comprised flavonoid (fig. 1), alkaloid (fig. 2), and polyphenol (fig. 3). Citroborate spray was used to detect the flavonoid contents compared to rutin as standard. The spot was easy to observe under $366 \mathrm{~nm}$ UV light. Based on fig 1., the flavonoid compound was detected on an $n$-hexane fraction, that characterized by the similar spot position between NHF and rutin.
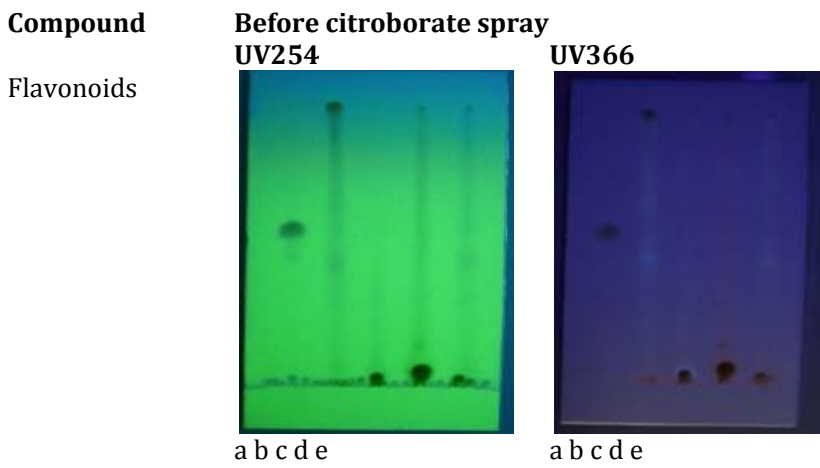

a b c d e

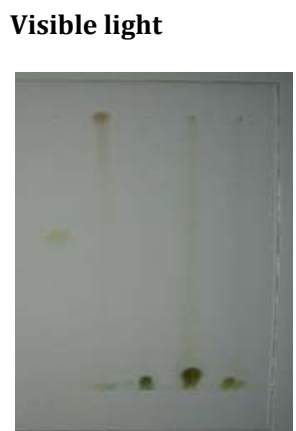

a b c d e

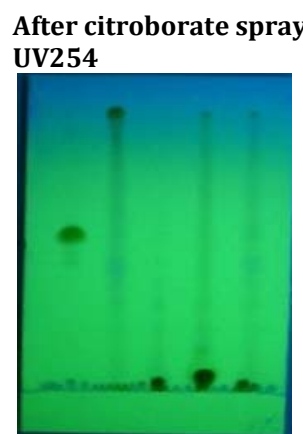

a b c d e

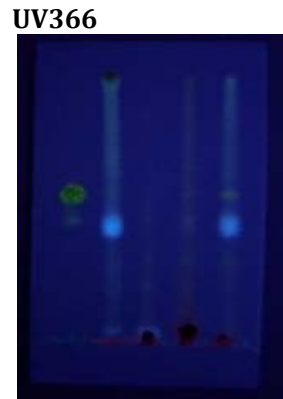

a b c d e

Fig. 1: Identification of flavonoid, Description: (a) MEE (b) NHF (c) EAF (d) WF (e) rutin, identification of alkaloid content (fig. 2) using Dragendorff reagent spotted both under 254 and $366 \mathrm{~nm}$ UV light. It suggested that mulberry leaves possess alkaloid compounds.

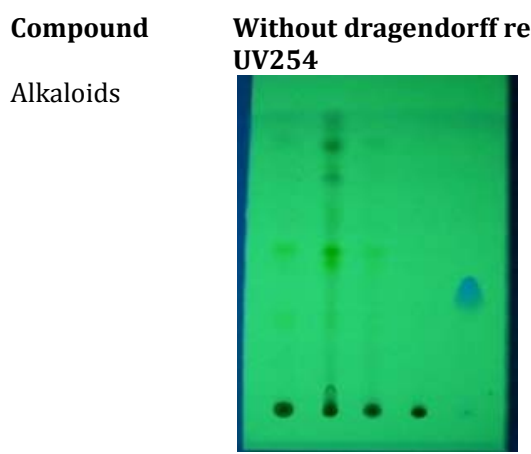

a b c d e
UV366

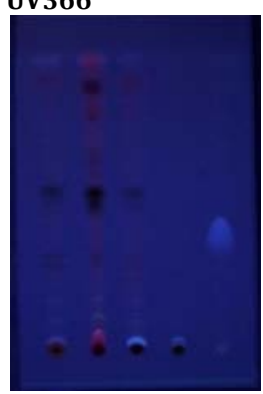

a b c d e
Visible light

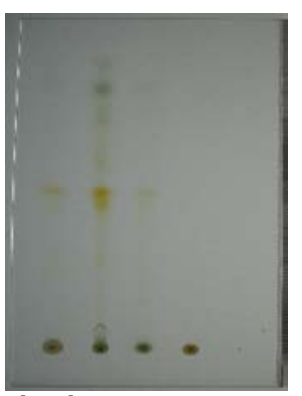

a b c d e
With dragendorff reagent

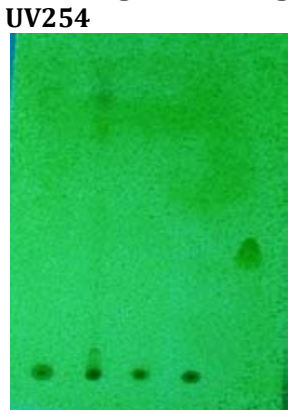

a b c d e

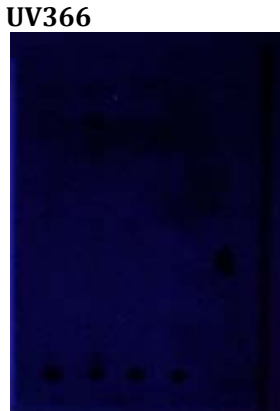

a b c d e

Fig. 2: Identification of alkaloid, description: (a) MEE (b) NHF (c) EAF (d) WF (e) quinine, after $\mathrm{FeCl}_{3}$ spray (fig. 3), polyphenol was identified under UV light. It comprised that mulberry contains polyphenol compounds

The measurement of triglyceride (TG) using the GPO-PAP method was described on table 1 . After $28 \mathrm{~d}$ of induction by HFD, the TG level increased significantly compared to the baseline $(\mathrm{p}<0.05)$. The effect of extract and fraction on TG level was shown on day 35 and 42. The EAF was the most active on lowering triglyceride levels compared to other extract and fractions. Even though the TG level was not lower as positive control gemfibrozil. 


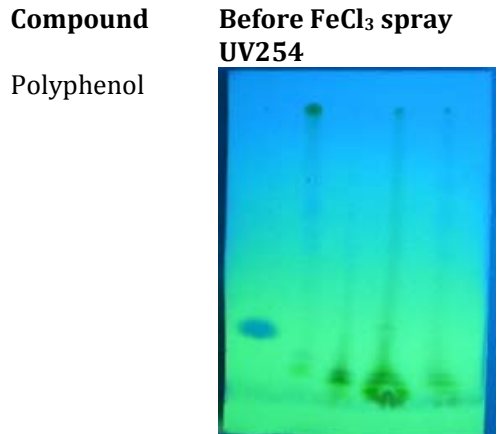

a b c d e

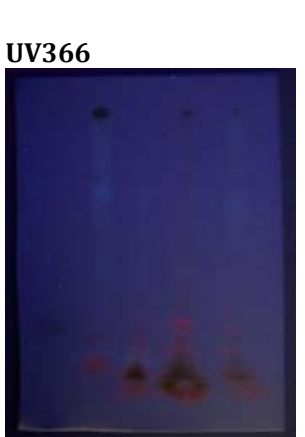

a b c d e
Visible light

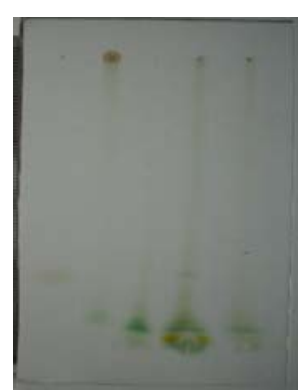

a b c d e
After $\mathrm{FeCl}_{3}$ spray

UV254

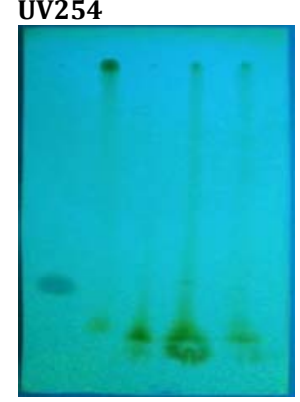

a b c de
UV366

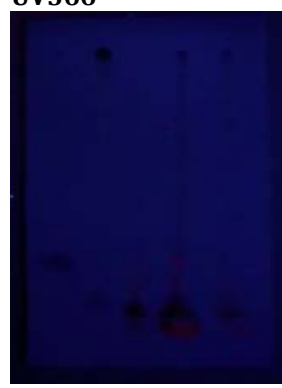

a b c d e

Fig. 3: Identification of polyphenol, description: (a) MEE (b) NHF (c) EAF (d) WF (e) tannins

Table 1: The blood triglyceride levels of rats

\begin{tabular}{|c|c|c|c|c|}
\hline \multirow[t]{2}{*}{ Group } & \multicolumn{4}{|c|}{ Triglyceride level (mean \pm SD, mg/dl) } \\
\hline & $\mathbf{D}_{\mathbf{0}}$ & $\mathbf{D}_{28}$ & $\mathbf{D}_{35}$ & $\mathbf{D}_{42}$ \\
\hline Normal control & $77.74 \pm 1.66$ & $70.67 \pm 3.08$ & $75.91 \pm 3.68^{\mathrm{bcd}}$ & $78.23 \pm 2.44^{\mathrm{bcd}}$ \\
\hline Negative control (HFD) & $81.04 \pm 2.49$ & $129.19 \pm 2.97$ & $116.29 \pm 2.43^{\mathrm{acd}}$ & $122.41 \pm 2.92^{\mathrm{acd}}$ \\
\hline Positive control Simvastatin & $78.96 \pm 4.51$ & $128.19 \pm 1,77$ & $109.52 \pm 2.23^{\mathrm{abd}}$ & $99.29 \pm 2.31^{\text {abd }}$ \\
\hline Positive control Gemfibrozil & $66.26 \pm 1.93$ & $127.21 \pm 2.06$ & $108.24 \pm 1.84^{\mathrm{abc}}$ & $90.60 \pm 4.99 \mathrm{abc}$ \\
\hline MEE & $67.01 \pm 4.04$ & $126.64 \pm 2.47$ & $113,99 \pm 2.84^{\mathrm{ab}}$ & $128.35 \pm 3.38^{\mathrm{abcd}}$ \\
\hline NHF & $64.93 \pm 1.93$ & $126.78 \pm 3.48$ & $115.65 \pm 4.04^{\mathrm{abc}}$ & $113.57 \pm 1.66^{\mathrm{abd}}$ \\
\hline EAF & $64.76 \pm 1.97$ & $127.49 \pm 1.91$ & $108.62 \pm 1.43^{\mathrm{abc}}$ & $104.89 \pm 2.70^{\mathrm{ab}}$ \\
\hline WF & $64.94 \pm 2.53$ & $124.10 \pm 1.38$ & $118.59 \pm 1.95^{\mathrm{ab}}$ & $145.06 \pm 5.35^{\mathrm{acd}}$ \\
\hline
\end{tabular}

Two-way Anova result $(\mathrm{p}<0.05)$, a: significantly different to the normal control, b: significantly different to the negative control, c: significantly different to the positive control simvastatin, d: significantly different to the positive control gemfibrozil

Another parameter for assessing antihyperlipidemic activity was total cholesterol (TC). Based on the result on table 2, HFD not only enhances TC but also TC. The TC level on day 28 significantly increased compared to the day $0(\mathrm{p}<0.05)$. Furthermore, the TC level on day 42 of EAF demonstrated a lower level of TC identical to the positive control. The comparison of TC level on day 35 and 42 indicated that longer duration of treatment related to the effectivity on TC lowering effect.

Table 2: Total blood cholesterol levels of rats

\begin{tabular}{|c|c|c|c|c|}
\hline \multirow[t]{2}{*}{ Group } & \multicolumn{4}{|c|}{ Cholesterol level (mean \pm SD, mg/dl) } \\
\hline & $\mathbf{D}_{\mathbf{0}}$ & $\mathbf{D}_{28}$ & $\mathbf{D}_{35}$ & $\mathbf{D}_{42}$ \\
\hline Normal control & $89.63 \pm 2.26$ & $82.60 \pm 2.03$ & $83.23 \pm 1.96^{\mathrm{bcd}}$ & $88.27 \pm 3.22^{\mathrm{bcd}}$ \\
\hline Negative control (HFD) & $89.90 \pm 2.78$ & $190.68 \pm 3.92$ & $172.67 \pm 3.92^{\mathrm{acd}}$ & $172.10 \pm 3.96^{\mathrm{acd}}$ \\
\hline Positive control Simvastatin & $88,96 \pm 1.49$ & $188.35 \pm 3.17$ & $157.88 \pm 2.53^{\mathrm{ab}}$ & $98.85 \pm 1.21^{\mathrm{ab}}$ \\
\hline Positive control Gemfibrozil & $84.54 \pm 1.54$ & $187.39 \pm 3.01$ & $158,13 \pm 2.90^{\mathrm{ab}}$ & $92.56 \pm 4.03^{\mathrm{ab}}$ \\
\hline MEE & $87.22 \pm 1.81$ & $186.85 \pm 2.88$ & $170.55 \pm 3.47 \mathrm{ad}$ & $120.76 \pm 1.92^{\mathrm{abcd}}$ \\
\hline NHF & $88.69 \pm 2.39$ & $189.72 \pm 3.65$ & $170.80 \pm 2.10^{\text {acd }}$ & $107.12 \pm 1.47 \mathrm{abcd}$ \\
\hline EAF & $88.02 \pm 1.38$ & $188,08 \pm 8.08$ & $167.57 \pm 1.48^{\mathrm{ad}}$ & $96.70 \pm 2.45^{\mathrm{abd}}$ \\
\hline WF & $89.23 \pm 2.53$ & $192.74 \pm 2.09$ & $171.43 \pm 3.54 \mathrm{acd}$ & $125.67 \pm 4.69$ abcd \\
\hline
\end{tabular}

Two-way Anova result ( $\mathrm{p}<0.05)$ : a: significantly different to the normal control, b: significantly different to the negative control, c: significantly different to the positive control simvastatin, d: significantly different to the positive control gemfibrozil profile of the average levels of triglycerides and total cholesterol on day 28 as shown in fig. 4 and 5.

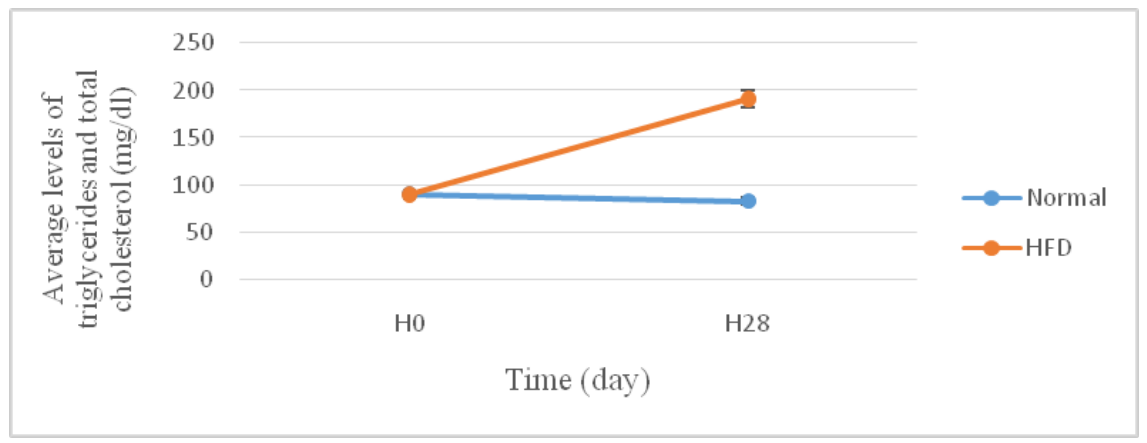

Fig. 4: Triglyceride levels at $D_{0}-D_{28}(\mathrm{mg} / \mathrm{dl})$ 


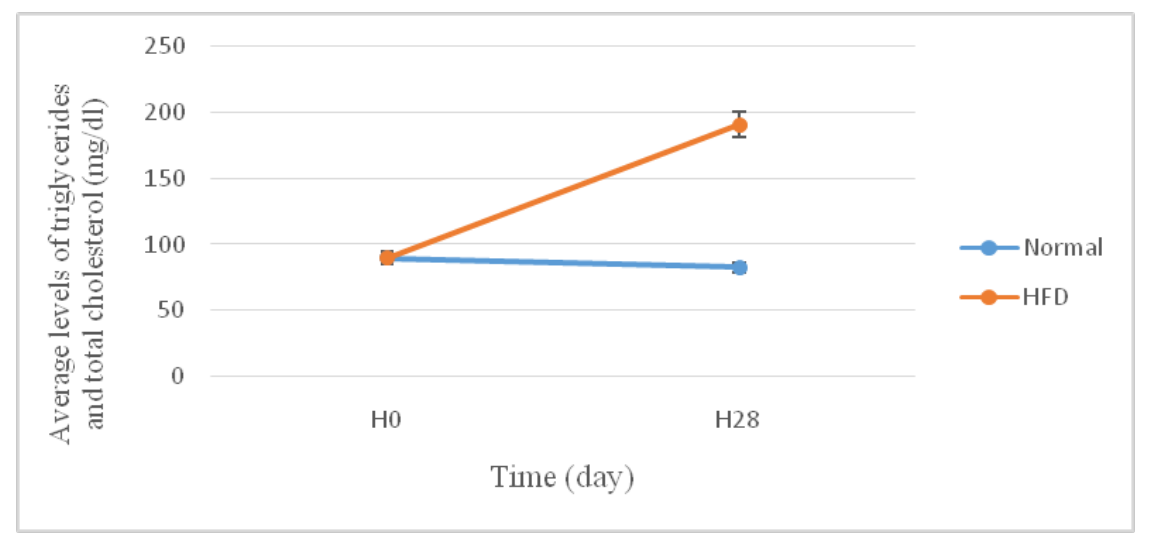

Fig. 5: Total cholesterol levels in rats at $D_{0}-D_{28}(\mathrm{mg} / \mathrm{dl})$

\section{DISCUSSION}

This study identified the presence of flavonoid compounds (fig. 1), which similarly reported regarding the content of phenolic acid and routine in flavonoids in mulberry leaves [9]. Mulberry leaves contain the following flavonoid compounds: quercetin 3-(-malonyl glycoside), routine, iso-quercetin, cyanidin 3-rutinoside, and cyanidin 3-glucoside. Quercetin is a flavonoid with four phenolic hydroxy groups at C5, C7, C3, and C4. Quercetin shows the effect of reducing triglyceride and total cholesterol levels [10].

Furthermore, in vivo experiments have shown that flavonoid and phenolic compounds in mulberry leaves can reduce lipids through various mechanisms. Mulberry leaf extract enriched with quercetin can activate the expression of AMP-activated protein kinase (AMPK) and peroxisome proliferator-activated receptor (PPAR)-a that helps to increase b-oxidation of free fatty acids and lipid breakdown [11].

Previous study also found that the isolate of ethanol extract of mulberry leaves contained alkaloid compounds with the main functional groups $\mathrm{O}-\mathrm{H}, \mathrm{C}-\mathrm{H}, \mathrm{C}-\mathrm{O}$, and $\mathrm{C}=\mathrm{C}$ [11]. Its component includes 1-deoxynojirimycin (DNJ) [12]. DNJ effectively suppresses the increase of blood glucose when consuming large amounts of carbohydrates [13]. Thereby it also lowers triglyceride and total cholesterol levels as it increases the lipoprotein lipase enzyme. Fig. 2 shows the results of the identification of alkaloids.

Fig. 3 shows that mulberry leaves contain polyphenolic compounds, which previous research similarly stated. Rich in polyphenol, mulberry leaf extract contains caffeic acid, quercetin, and hydroxy flavone, which can decrease lipogenesis by regulating the activity of synthetic fatty acids (FAS), glycerol-3-phosphate acyltransferase (GPAT), sterol regulatory element-binding proteins (SREBP)-1c, and $\mathrm{X}$ hearts (LXR) receptors [14].

Measurement of triglyceride levels in blood serum used the GPO-PAP (Glycerol Peroxidase Phosphate Acid) colorimetric enzymatic method with the principle of starting with the hydrolysis of lipoprotein lipase enzymes into glycerol and free amino acids. Lipase will form a color complex that can be measured using spectrophotometry. Determination of triglyceride levels was carried out four times, namely on day 0 (D0) as the initial blood collection, on day 28 (D28) to measure the hyperlipidemia condition of test animals after being given a high-fat diet and PTU for $28 \mathrm{~d}$, measurements on day 35 (D35) and 42 (D42). The latest aims to determine the optimal triglyceride levels after being treated. In the normal control group, the HFD control, mulberry leaf extract, and water fraction experienced an increase in triglyceride levels as shown in table 1.

The increase in triglyceride levels was associated with the administration of HFD for $28 \mathrm{~d}$. HFD can cause an increase in fat cell size through lipogenesis that initiates an increase in the number of cells from adipocytes through proliferation and transcription of sterol regulatory element-binding protein (SREBP)-1. Meanwhile, PTU is an anti-thyroid substance that can inhibit thyroid hormone and increase triglyceride and cholesterol levels in the blood [14].
In the other treatment groups, there was a decrease in triglyceride levels. However, gemfibrozil is more effective in lowering triglyceride levels than simvastatin. Gemfibrozil can increase lipolysis and hepatic fatty acid intake. It also decreased hepatic triglyceride production and stimulated reverse cholesterol transport [15]. The mechanism of action of gemfibrozil in lowering triglycerides is through binding to the Peroxisome Proliferator-Activated Receptors (PPARS), receptors that regulate gene transcription. This binding increased fatty acid oxidation and lipoprotein lipase activity. It also decreased Apo C-III expression and eventually triglycerides level. Apo C-III is a small polypeptide that is freely transferred from one lipoprotein to another by activating lipoprotein lipase to degrade triglycerides or triacylglycerols in the chylomicron and VLDL components. Gemfibrozil can increase cholesterol's secretion into bile, inhibit triglycerides, and suppress the release of free fatty acids from adipose tissue [16].

The ethyl acetate fraction group can reduce triglyceride levels comparable to both positive and negative controls, while the nhexane fraction was equivalent to the positive control's simvastatin. This finding explains that mulberry leaf extract and fraction can reduce triglyceride levels, although not as good as simvastatin or gemfibrozil. Mulberry leaves contain flavonoid compounds, alkaloids, and polyphenols which are known to reduce triglyceride levels through the mechanism of increasing bile acid excretion [7].

The method used in measuring total cholesterol level is CHOD-PAP (Cholesterol Oxidase Deaminase Peroxidase Aminoantipyrine) with the principle that the formation of cholesterol follows enzymatic hydrolysis and oxidation. The initial reaction step of the enzymatic method is the hydrolysis of cholesterol esters to form free cholesterol, followed by an oxidation step that uses oxygen to produce hydrogen peroxide $\left(\mathrm{H}_{2} \mathrm{O}_{2}\right)$ through the formation of reduced colored oxidation. Table 2 shows the measurement of total cholesterol levels using the CHOD-PAP method. The increase in total cholesterol levels of plasma in this study resulted from the increasing consumption of saturated fatty acids. A saturated, fattyacid diet can increase blood cholesterol concentrations by $15-25 \%$. Fatty acids can be converted into acetyl CoA through-oxidation. Acetyl $\mathrm{CoA}$ is a cholesterol precursor, so an increase in the amount of this precursor can cause an increase in cholesterol levels in the blood. This occurrence will impact the disruption of metabolic processes and the excretion of cholesterol in the body, where total serum cholesterol levels will increase.

Mulberry leaf extract, n-hexane fraction, and water fraction were significantly different among the control groups. The ethyl acetate fraction also showed significant differences between normal, negative, and gemfibrozil positive controls. Using two way ANOVA, the analysis showed a crucial result $(p>0.005)$. The overall results imply that the difference between the measurements of total cholesterol levels among test groups on the $42^{\text {nd }}$ day is significant. This was indicated by the ethyl acetate fraction having the ability to lower total cholesterol comparable to simvastatin positive control.

Changes in triglyceride levels on day 28 were the results of different feed inductions. Fig. 4 and 5 showed that the normal group 
experienced a decrease in triglyceride levels and an increase in total cholesterol, which is contrary to the HFD and PTU-induced groups. The results of feed induction demonstrated success in the hyperlipidemic conditions of the test animals. Increased levels of triglycerides in the blood resulted from excessive glucose intake, in that glucose in the blood will be converted into lipids through lipogenesis. The process of lipogenesis produces energy needed to automatically produce lipids beyond their normal limit. In addition, increased triglyceride level also affects chylomicrons and leads to very-low-density lipoprotein (VLDL). Chylomicrons serve to carry triglycerides from the diet, whereas VLDL serves as a means for exporting triglycerides to peripheral tissues [17].

The HFD used in this experiment consisted of Comfeed PARS, wheat flour, rice flour, corn flour, fish meal, mung bean flour, cholesterol, folic acid, lard, beef fat, and water [18]. Judging from the compositions of the feed, most of them are high in carbohydrates. Giving a high-carbohydrate diet causes an increase in blood glucose levels more quickly compared to that of the high-fat diet, which can lead to hyperglycemia and hyperinsulinemia.

Hyperinsulinemia is a condition that causes insulin resistance, resulting in decreased lipoprotein lipase activity. The lower the activity of this enzyme, the higher the level of triglycerides in the blood. Diet settings given to the test animals are the same as body weight settings so that it affects the activity of the hormone leptin. Consumption of foods rich in carbohydrates and fats will cause an increase in the amount of fat stored in adipose tissue, especially under the skin and abdominal cavity. If not used immediately, the fats will be stored as triglycerides and cause weight gain. This results from a large number of fat cells in the body (hyperplastic) and the increase in the size of the existing fat cells (hypertrophic) [19].

Mulberry leaves contain quercetin, a flavonoid that can lower triglycerides by blocking the secretion of apoB 100 in Cacocells2 and can reduce MTP activity which plays a role in the formation of lipoproteins to catalyze the transfer of lipid molecules to Apo-B. Quercetin can also inhibit the activity of the HMG CoA reductase enzyme that acts as a cholesterol maker. Therefore, quercetin in mulberry leaves can play a role in lowering cholesterol levels [20].

\section{CONCLUSION}

In conclusion, ethyl acetate fraction of mulberry leaves (Morus australis Poir.) was the best in reducing triglyceride and total cholesterol levels in rats given HFD and PTU.

\section{FUNDING}

Nil

\section{AUTHORS CONTRIBUTIONS}

All the authors contributed equally.

\section{CONFLICT OF INTERESTS}

Declared none

\section{REFERENCES}

1. Alvarez Ramirez AA, Pelaez JL, Bermudez IM, Gordon Botero JY. Prevalence of hyperlipidemia and its associated factors in university students in Colombia. Heliyon. 2020;6(11):e05417. doi: 10.1016/j.heliyon.2020.e05417, PMID 33195846.

2. Hill MF, Bordoni B. Hyperlipidemia. StatPearls. Treasure Island (FL): StatPearls publishing. Copyright; 2021.

3. Grundy SM, Stone NJ, Bailey AL, Beam C, Birtcher KK, Blumenthal RS. Circulation 2019/AACVPR/AAPA/ABC/ACPM/ADA/AGS/APhA/ASPC/NL A/PCNA guideline on the management of blood cholesterol: A report of the American College of Cardiology/American Heart Association Task Force on Clinical Practice Guidelines. 2018:139(25):e1082-e143.

4. Bozzetto L, Della Pepa G, Vetrani C, Rivellese AA. Dietary impact on postprandial lipemia. Front Endocrinol (Lausanne).
2020;11:337. doi: 10.3389/fendo.2020.00337, PMID 32733374 .

5. Jan B, Parveen R, Zahiruddin S, Khan MU, Mohapatra S, Ahmad S. Nutritional constituents of mulberry and their potential applications in food and pharmaceuticals: a review. Saudi J Biol Sci. 2021;28(7):3909-21. doi: 10.1016/j.sjbs.2021.03.056, PMID 34220247.

6. Valacchi G, Belmonte G, Miracco C, Eo H, Lim Y. Effect of combined mulberry leaf and fruit extract on liver and skin cholesterol transporters in high fat diet-induced obese mice. Nutr Res Pract. 2014;8(1):20-6. doi: 10.4162/nrp.2014.8.1.20, PMID 24611101.

7. Kim JH, Doh EJ, Lee G. Quantitative comparison of the marker compounds in different medicinal parts of morus alba L. using high-performance liquid chromatography-diode array detector with chemometric analysis. Molecules. 2020;25(23):5592. doi: $10.3390 /$ molecules 25235592.

8. Lee Y, Lee E, Lee M-S, Lee S, Kim C, Kim Y. Hypolipidemic effect of mulberry leaf extract in rats fed a high-cholesterol diet (P06014-19). Curr Dev Nutr. 2019;3(Supplement_1);Suppl 1:06-1419. doi: $10.1093 / \mathrm{cdn} / \mathrm{nzz} 031$. P06-014-19.

9. Megawati AM, Embu Y, Ikram K. Uji aktivitas antioksidan ekstrak etanol daun murbei (Morus alba L.) asal Kupang, Nusa Tenggara Timur dengan metode DPPH (2,2 diphenil-1picrylhydrazyl). Techno. J Penelitian. 2020;08(1):246-52.

10. Kobayashi Y, MM, Kamei A, KA, TH. Effects of morus alba L. (Mulberry) leaf extract in hypercholesterolemic mice on suppression of cholesterol synthesis. J Pharmacogn Nat Prod. 2016;2:1. doi: 10.4172/2472-0992.1000113.

11. Lallo S. A HL, Hardianti B, Bahar RA. Identification and characterization of compound of leaf extract mulberry (Morus alba L.). J Pharm Med Sci. 2018;2(2).

12. Song $\mathrm{W}$, Wang HJ, Bucheli P, Zhang PF, Wei DZ, Lu YH. Phytochemical profiles of different mulberry (Morus sp.) species from China. J Agric Food Chem. 2009;57(19):9133-40. doi: 10.1021/jf9022228, PMID 19761189.

13. Nakamura S, Hashiguchi M, Yamaguchi Y. Hypoglycemic effects of morus alba leaf extract on postprandial glucose and insulin levels in patients with type 2 diabetes treated with sulfonylurea hypoglycemic agents. J Diabetes Metab. 2011;02(9). doi: 10.4172/2155-6156.1000158.

14. Chang YC, Yang MY, Chen SC, Wang CJ. Mulberry leaf polyphenol extract improves obesity by inducing adipocyte apoptosis and inhibiting preadipocyte differentiation and hepatic lipogenesis. J Funct Foods. 2016;21:249-62. doi: 10.1016/j.jff.2015.11.033.

15. Nuralifah N, Wahyuni W, Parawansah P, Dwi Shintia U. Uji aktivitas antihiperlipidemia ekstrak etanol daun notika (Arcboldiodendron calosericeum Kobuski) terhadap kadar kolesterol total tikus (Rattus norvegicus) jantan galur wistar. J Syifa Sci Clin Res. 2019;2(1):1-10. doi: 10.37311/jsscr.v2i1.2704.

16. Roy A, Pahan K. Gemfibrozil, stretching arms beyond lipid lowering. Immunopharmacol Immunotoxicol. 2009;31(3):33951. doi: 10.1080/08923970902785253, PMID 19694602.

17. Siregar RNI. The effect of Eugenia polyantha extract on LDL cholesterol. J Majority. 2015;4(5):85-92.

18. Speakman JR. Use of high-fat diets to study rodent obesity as a model of human obesity. Int J Obes (Lond). 2019;43(8):1491-2. doi: 10.1038/s41366-019-0363-7, PMID 30967607.

19. Veilleux A, Caron-Jobin M, Noël S, Laberge PY, Tchernof A. Visceral adipocyte hypertrophy is associated with dyslipidemia independent of body composition and fat distribution in women. Diabetes. 2011;60(5):1504-11. doi: 10.2337/db101039, PMID 21421806.

20. Sari DP, Yustiantara PS, Paramita N, Wirasuta I. Uji aktivitas Antibakteri ekstrak etanol buah Lada Hitam (Piper nigrum L.) terhadap bakteri Propionibacterium acnes. J Farmasi Udaya. 2014;3(2). Available from: https://ojs.unud.ac.id/ index.php/jfu/article/view/12051. [Last accessed on 09 Oct 2021]. 